\title{
High Rate of MCR-1-Producing Escherichia coli and Klebsiella pneumoniae among Pigs, Portugal
}

\author{
Nicolas Kieffer, Marta Aires-de-Sousa, Patrice Nordmann, Laurent Poirel
}

The mcr-1 (mobile colistin resistance 1) gene, which encodes phosphoethanolamine transferase, has been recently identified as a source of acquired resistance to polymyxins in Escherichia coli. Using the SuperPolymyxin selective medium, we prospectively screened 100 pigs at 2 farms in Portugal for polymyxin-resistant Enterobacteriaceae and recovered 98 plasmid-mediated MCR-1-producing isolates. Most isolates corresponded to nonclonally related $E$. coli belonging to many sequence types; we also found 2 Klebsiella pneumoniae sequence types. The mcr-1 gene was carried on IncHI2 or IncP plasmid backbones. Our finding of a high rate of MCR-1 producers on 2 pig farms in Portugal highlights the diffusion of that colistin-resistance determinant at the farm level. The fact that the pigs received colistin as metaphylaxis in their feed during the 6 weeks before sampling suggests selective pressure.

$\mathrm{T}$ he progressive global increase of antimicrobial drug resistance in Enterobacteriaceae is worrisome, and adding to the concern is the recent discovery of the plasmid-mediated mobile colistin resistance (MCR) genes mcr-1 and $m c r-2(1,2)$. These genes encode phosphoethanolamine transferases, which add a phosphoethanolamine group to the lipid A of the lipopolysaccharide, leading to gram-negative bacteria resistance to polymyxins (3). Since its discovery, the $m c r-1$ gene has been identified almost worldwide, mostly in animal and environmental samples (3) and to a lesser extent in human clinical samples (4). The $m c r-1$ gene has often been identified from Escherichia coli strains recovered from pigs $(3,5-8)$. More recently, the $m c r-2$ gene, which shares $76.8 \%$ nt identity with $m c r-1$, has been identified from a single $E$. coli isolate recovered from a pig in Belgium (2). The genetic element related to the $m c r-2$ gene and possibly involved in its acquisition is insertion sequence (IS) ISEc69.

Author affiliations: Université de Fribourg, Fribourg, Switzerland (N. Kieffer, P. Nordmann, L. Poirel); Escola Superior de Saúde da Cruz Vermelha Portuguesa, Lisbon, Portugal (M. Aires-de-Sousa); University of Lausanne and University Hospital Centre, Lausanne, Switzerland (P. Nordmann)

DOI: https://doi.org/10.3201/eid2312.170883
The $m c r-1$ gene has been identified on a large variety of plasmids, such as IncI2, IncX4, IncHI2, IncP, IncFI, IncFII, IncFIB, and IncY $(3,9,10)$. The genetic context of the $m c r-1$ gene always includes the $m c r-1$ cassette, as previously described $(11,12)$. In addition, ISApll is often found upstream of the $m c r-1$ gene. It has been recently shown that a second copy of ISApl1 may be found downstream of the $m c r-1$ gene, therefore bracketing the $2.6-\mathrm{kb} m c r-1$ cassette and forming the composite transposon Tn6330, demonstrated to be functional and responsible for the transposition of $m c r-1(13,14)$.

We speculate that the emergence and further dissemination of the $m c r-1$ and -2 genes occurred from pigs and that ISApl and ISEc69, respectively, were the main genetic elements involved in that process. We recently demonstrated that Moraxella spp. are sources of $m c r$-like encoding genes (15); M. pluranimalium has been identified as the progenitor of the $m c r-2$ gene (16). Of note, all Moraxella spp. are widespread in pigs (17), thus allowing speculation that the whole genetic process that originally led to the emergence of the $m c r$-like genes occurred in those animals.

Worldwide, colistin is widely used in veterinary medicine for different purposes, including treatment of enteric infections, prophylaxis or metaphylaxis (18), and as growth promoter in several countries (19). Despite this selective pressure, studies reporting identification of colistin-resistant Enterobacteriaceae in veterinary medicine remain scarce, although an overall low prevalence of those resistant strains was noticed in Europe $(8,10,20,21)$.

To evaluate the prevalence and genetic characterization of colistin-resistant Enterobacteriaceae on pig farms, we performed a prospective epidemiologic survey. The study was conducted in Portugal (the fifth largest polymyxin consumer in Europe), where colistin is heavily used in veterinary medicine (22).

\section{Materials and Methods}

\section{Isolates and Susceptibility Testing}

On 1 day in June 2016, we collected 100 rectal swab samples from pigs on 2 pig farms in Portugal, $30 \mathrm{~km}$ apart. These farms, harboring $\approx 3,000$ pigs each, are production 
holdings, where piglets are born and fattened before being delivered to slaughterhouses (23). All pigs sampled were $10-11$ weeks of age. When the pigs were $5-10$ weeks of age, their feed included colistin $(0.5 \%)$, amoxicillin $(0.5 \%)$, and zinc oxide $(0.15 \%)$. The weekly dose of colistin in the regimen was $\approx 0.06 \mathrm{~g} / \mathrm{kg}$. Overall, all pigs received $\approx 5.5 \mathrm{~g}$ colistin for metaphylaxis over 6 weeks.

We incubated rectal swab samples overnight at $37^{\circ} \mathrm{C}$ in Luria-Bertani broth supplemented with $1 \mu \mathrm{g} / \mathrm{mL}$ colistin. The next day, to select for colistin-resistant gramnegative isolates, we inoculated each enrichment tube onto SuperPolymyxin selective agar medium that contained $3.5 \mu \mathrm{g} / \mathrm{mL}$ colistin and $10 \mu \mathrm{g} / \mathrm{mL}$ daptomycin (ELITechGroup, Signes, France) (24). We identified colistin-resistant isolates recovered from SuperPolymyxin plates with API 20E (bioMérieux, La Balme les Grottes, France). We performed antimicrobial drug susceptibility testing by using the disk-diffusion method according to Clinical and Laboratory Standards Institute recommendations, on Muller-Hinton agar plates, except for colistin, for which we evaluated MICs for colistin by broth microdilution in cation-adjusted Muller-Hinton broth (Bio-Rad, Cressier, Switzerland), as recommended by the Clinical and Laboratory Standards Institute (25).

\section{Molecular Analyses}

Acquired colistin-resistance genes $m c r-1$ and $m c r-2$ were identified by PCR, with use of specific primers as reported (14), and amplicons were further sequenced by Microsynth (Balgach, Switzerland). We identified extended-spectrum $\beta$-lactamase (ESBL)-encoding genes by using primers specific for detection of $b l a_{\mathrm{TEM}}, b l a_{\mathrm{SHV}}$, and $b l a_{\mathrm{CTX}-\mathrm{M}}$ genes $(26,27)$. The plasmidborne chloramphenicol gene floR was sought by using specific primers (28) among isolates exhibiting resistance to chloramphenicol. The clonal relationship of the colistin-resistant isolates was evaluated by pulsedfield gel electrophoresis, as described previously (29), and multilocus sequence typing was performed for a representative strain of each pulsotype. We assigned sequence types (STs) by using the multilocus sequence typing databases for E. coli (http://mlst.warwick.ac.uk/mlst/dbs/Ecoli) and K. pneumoniae (http://bigsdb.pasteur.fr/klebsiella/klebsiella.html). The phylogenetic group of $E$. coli isolates was determined with the PCR-based Clermont method as described previously (30).

\section{Conjugation Experiments and Plasmid Analyses}

We performed conjugation assays on filters with azide-resistant E. coli J53 as the recipient strain. MCR-1 producers and the J53 isolate were cultured overnight in Luria-Bertani broth. To reach the logarithmic phase, the donor and recipient strains were subcultured in fresh Luria-Bertani broth for $3 \mathrm{~h}$. We subsequently mixed the samples at a ratio of
10:1 and deposited $100 \mu \mathrm{L}$ of this mix onto $22-\mu \mathrm{m}$ filters, which we then incubated for $5 \mathrm{~h}$ at $37^{\circ} \mathrm{C}$ on Luria-Bertani agar plates. After the incubation, filters were resuspended in $0.85 \% \mathrm{NaCl}$, and we plated $250 \mu \mathrm{L}$ of this mixture onto selective Luria-Bertani plates containing azide $(100 \mu \mathrm{g} /$ $\mathrm{mL})$ and colistin $(1 \mu \mathrm{g} / \mathrm{mL})$. PCR was used to check all $E$. coli transconjugants for the $m c r-1$ gene.

We typed plasmids carrying the $m c r-1$ gene from $E$. coli transconjugants by using the PCR-based replicon typing method (31). The size of the plasmid was obtained after Kieser extraction (32) and agarose gel electrophoresis; we used as a reference $E$. coli 50192 isolate containing 4 characterized plasmids ( $154 \mathrm{~kb}, 66 \mathrm{~kb}, 48 \mathrm{~kb}$, and $7 \mathrm{~kb}$ ).

\section{Results}

From the 100 rectal swab samples collected, we recovered 108 colistin-resistant isolates from the SuperPolymyxin agar plates and identified 90 as E. coli, 17 as K. pneumoni$a e$, and 1 as Proteus mirabilis. Of the 108 colistin-resistant isolates, 98 were positive for the $m c r-1$ gene. Colistin MICs for all MCR-1-producing isolates ranged from 4 to $32 \mu \mathrm{g} /$ $\mathrm{mL}$ (Table). Among these positive isolates, 10 showed an ESBL phenotype. Sequencing revealed that all mor-positive isolates possessed a gene that was $100 \%$ identical to mcr-1. All MCR-1-producing isolates possessed the blaTEM-1 gene, and all ESBL producers possessed the bla $a_{\text {СTX- }}$ ${ }_{\mathrm{M}-2}$ gene. All MCR-1-producing isolates were resistant to penicillins and tetracycline, $97.9 \%$ were resistant to sulfamethoxazole/trimethoprim, $96 \%$ were resistant to tobramycin, and $84.7 \%$ were resistant to chloramphenicol. Among the chloramphenicol-resistant isolates, $56 \%$ were positive for the $f l o R$ resistance gene. No $\mathrm{mcr}$-2-positive isolate was identified in our samples.

Pulsed-field gel electrophoresis identified 19 distinct $E$. coli clones from the first farm sampled and 18 from the second (Table). The isolates belonged to 15 STs (ST10, ST23, ST38, ST46, ST101, ST156, ST6453, and 8 new STs); only 2 (ST10 and ST101) were detected on both farms. Phylogenetic typing showed that each $E$. coli isolate belonged to 1 of the phylogroups A, B1, C, D, E, or F. No extraintestinal and virulent $\mathrm{B} 2$ phylogroup was detected among all $E$. coli isolates. In addition, we identified $2 \mathrm{~K}$. pneumoniae STs (1 clone per farm), ST45 and ST1563.

Conjugation followed by PCR-based replicon typing analysis showed that the $m c r-1$ gene was carried on different plasmids (Table). The $m c r-1$ gene was identified on IncHI2 (54\%), IncP (38\%), and IncX4 (8\%) plasmids. Conjugation experiments showed that resistance to sulfamethoxazole/ trimethoprim and sulfonamides was systematically co-transferred along with the $m c r-1$ gene when carried by IncHI2 plasmids and that resistance to tetracycline, tobramycin, chloramphenicol, and amoxicillin was also most often cotransferred by IncP plasmids (Table). Conversely, the $m c r-1$ 
Table. Genetic features associated with MCR-1-producing Escherichia coli and Klebsiella pneumoniae isolates from pigs, Portugal*

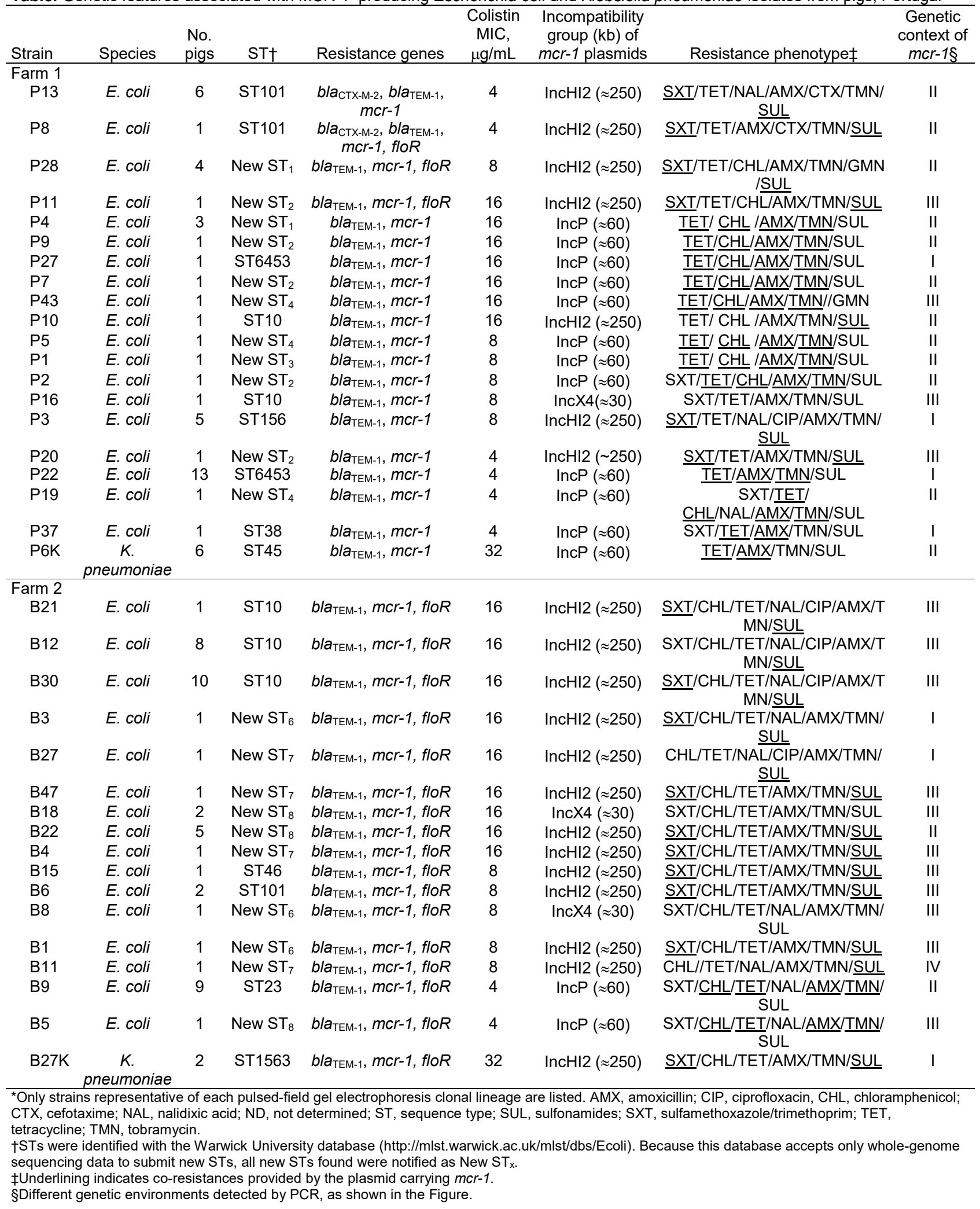


gene was the only resistance determinant when located on IncX4 plasmids. Of note, IncP-type plasmids carrying $\mathrm{mcr}-1$ were predominant on the first farm, whereas IncHI2 plasmids were predominant on the second farm.

By PCR mapping using previously published primers $(12,13)$, in all isolates we identified the $\approx 2.6-\mathrm{kb} \mathrm{mcr}-1$ cassette in association with 0,1 , or 2 copies of insertion sequence ISApl1, depending on the isolates tested (Table; Figure). In addition, we found a genetic structure not previously reported in 1 isolate that consisted of a truncated ISApl 1 element upstream of the $\mathrm{mcr}-1$ cassette. That structure, inserted into a kinase gene onto an IncHI2 plasmid, corresponded to a truncated version of transposon $\operatorname{Tn} 6330$ previously reported, with a 2-bp AG direct repeat bracketing the $\Delta \mathrm{IS}$ Apl1-mcr-1 structure, suggesting a former insertion event through a transposition mechanism (Figure).

\section{Discussion}

Prevalence of MCR-1-producing Enterobacteriacae isolates, mainly E. coli, from 2 pig farms in Portugal was high. So far, the mcr-1 gene has been identified mainly in animal samples, rarely in environmental and human samples (3,4,33-36). Previous studies describe the occurrence of MCR-1 producers in swine; prevalence in Europe ranged from $0.5 \%$ to $13.5 \%(6,8,36,37)$ and in China up to $20.6 \%$ (1). In our study, we detected an extremely high rate of MCR-1-producing Enterobacteriaceae, finding the $m c r-1$ gene in isolates from $98 \%$ of pigs tested. We identified an MCR-1-producing K. pneumoniae among the pigs, which is noteworthy considering the infrequent recovery of $K$. pneumoniae from animals. Nevertheless, most of the $m c r$ - 1 -positive isolates identified here were $E$. coli, as is reported in most epidemiologic studies (3). For the same pigs that had been screened (by nasal swabs) for methicillinresistant Staphylococcus aureus, the rate of colonization was very high (99\%); 2 main spa types of clone ST398 were identified (23).
Our study was performed with samples from pigs, and it would be of interest to conduct similar studies of humans. In France, a survey performed in a hospital during February-May 2016 (38) showed a high rate (23\%) of fecal carriage with intrinsic colistin-resistant gram-negative isolates but a low rate (1.4\%) of acquired polymyxin resistance; no $m c r-1$ or $m c r-2$ genes were identified. A retrospective study focusing on Salmonella isolates was previously performed in Portugal, and MCR-1 producers were reportedly found in humans and pork (39). No MCR-2-producing isolate was identified in our study, although this gene was also identified in pigs (2).

We used the newly developed SuperPolymyxin medium for our prospective epidemiologic study. The fact that no colistin-susceptible strain was recovered during the screening further highlights the excellent specificity of this medium.

Unexpectedly, we found that the studied collection of MCR-1 producers was highly diverse; we identified many STs and genetic features associated with $m c r-1$. The rate of $m c r-1$ in our study was very high and caused by the dissemination of neither a single clone nor a plasmid. This high diversity could be explained by 2 key elements. First, considering that the selective pre-enrichment with LuriaBertani broth supplemented with $1 \mu \mathrm{g} / \mathrm{mL}$ of colistin and subsequent culturing on the Superpolymyxin medium exhibits a high sensitivity, such a prospective survey may detect higher rates of colistin-resistant isolates than would previous studies. Second, the presence of colistin in the pig food on the 2 farms studied probably represents an efficient selective pressure for MCR-1 acquisition. Findings of similar and comparative studies performed in countries that do not use polymyxins in animals, such as Norway or Finland, would be of interest.

Several STs of $E$. coli identified in this study were similar to those of other MCR-1-producing isolates reported from other studies. As an example, ST10 E. coli producing

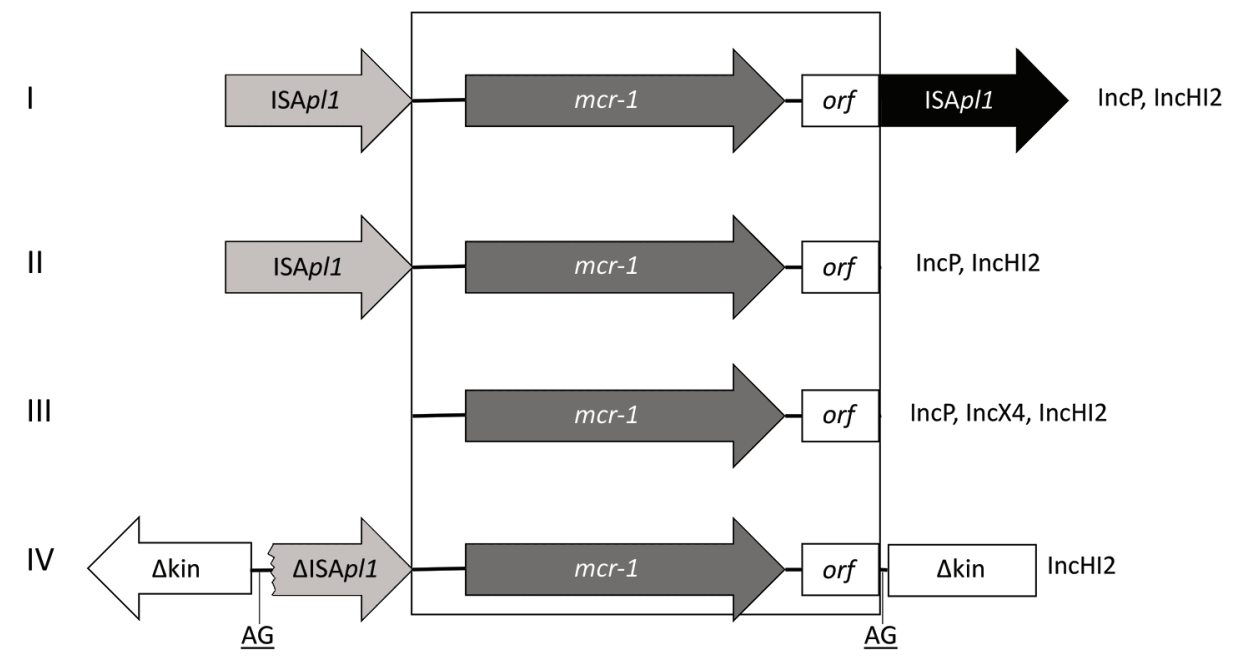

Figure. Genetic environments associated with the $m c r-1$ (mobile colistin resistance 1) gene detected in select Enterobacteriacae isolates from pigs, Portugal, by PCR. I) 1 copy of ISApl1 associated with $m c r-1$ in $5^{\prime}$ region; II) 2 copies of ISAp/1 in $5^{\prime}$ and $3^{\prime}$ regions of $m c r-1$; III) no copy of ISApl1 associated with $m c r-1$; IV) truncated copy of ISAp/1 associated with $m c r-1$ in $5^{\prime}$ region inserted in a kinase gene. IS, insertion sequence; orf, open reading frame. 
MCR-1 was recovered from swine farms in Germany and in clinical samples in India and South Africa $(6,11,40)$. In South Africa, ST101 E. coli was identified from a patient with a urinary tract infection (11). ST156 E. coli was identified at a hospital in China and in a muscovy duck in China, where it was co-producing MCR-1 and NDM (New Delhi metallo- $\beta$-lactamase) -5 carbapenemase $(41,42)$. We showed that all $E$. coli isolates belonged to a commensal population and not to extraintestinal pathogenic strains, which is consistent with findings of other studies (3) and in line with the design of our study, which was analyzing the colonizing gut flora.

We showed that the $m c r-1$ gene was carried by a diversity of plasmids. However, most plasmids recovered from the first farm were $\approx 60$-kb IncP plasmids, whereas those from the second farm were $\approx 250$-kb IncHI2 plasmids. Only $3 \mathrm{STs}$ possessed a $\approx 30-\mathrm{kb}$ IncX 4 plasmid carrying the $m c r-1$ gene, which contrasts with other studies that have shown this type of plasmid to be predominant (43). In accordance with what has been observed with other characterized IncX4 plasmids, we found no other resistant determinant associated with $m c r-1$ on that plasmid type. IncP and IncHI2 plasmids carried other resistance determinants associated with $m c r-1$. Remarkably, we found no IncI2-type plasmid carrying $\mathrm{mcr}$ - 1 in those isolates, although they have often been reported in the literature $(1,3)$.

Analysis of the genetic features associated with the $m c r-1$ gene further highlights that it was probably originally acquired by a transposition mechanism and that ISApl1 played a major role; further truncations or rearrangements led to the stabilization of this structure, as suggested by Snesrud et al. (44). We also identified the entire composite transposon Tn6330 comprising 2 copies of ISApll bracketing the $m c r-1$ cassette (13). Because this entire transposon was detected in some isolates of this collection in addition to other defective versions of it, we can speculate that this structure may still be mobilizable and continue to disseminate between different genetic locations.

In summary, the rate of pig colonization with MCR-1producing Enterobacteriaceae was high at the 2 farms we sampled, showing substantial diversity of species, clonality, and genetic aspects. Even if these results suggest that colistin constitutes a major driving force for selecting plasmids carrying the $m c r-1$ gene, the occurrence of the $b l a_{\text {TEM-1 }}$ gene on the same plasmid indicates that $\beta$-lactams might also be co-selecting for colistin resistance through the acquisition of such plasmids. In addition, this study showed that SuperPolymyxin is an efficient medium for screening colistin-resistant isolates from animal samples and performing such epidemiologic surveys. Last, considering that a recent report from Germany identified pig farms as potential sources of environmental contamination for
MCR-1-producing E. coli (6), our data strongly indicate the need for screening farm environments in Portugal, to evaluate the extent to which the spread of those resistant bacteria has already occurred and, therefore, to better measure the risk to human health.

\section{Acknowledgments}

We are grateful to S. Kumar-Malhotra for the gift of the MCR-2-producing E. coli strain.

This work has been funded by the University of Fribourg; by grants from the Animal Health and Welfare ERA-Net project, Switzerland; by the Office Fédéral de la Santé Publique, Bern, Switzerland (grant no. 16009294); by project PTDC/DTP-EPI/ 0842/2014 from Fundação para a Ciência e a Tecnologia, Portugal; and by the Novartis Foundation for Medical-Biological Research.

An international patent form has been filed on behalf of the University of Fribourg (Switzerland) corresponding to the SuperPolymyxin selective medium.

Mr. Kieffer is a PhD student in microbiology at the University of Fribourg, Switzerland. His main activities are related to the identification of acquired polymyxin and carbapenem resistance mechanisms in gram-negative bacteria, with a focus on the genetics of resistance gene acquisition.

\section{References}

1. Liu YY, Wang Y, Walsh TR, Yi LX, Zhang R, Spencer J, et al. Emergence of plasmid-mediated colistin resistance mechanism MCR-1 in animals and human beings in China: a microbiological and molecular biological study. Lancet Infect Dis. 2016;16:161-8. http://dx.doi.org/10.1016/S1473-3099(15)00424-7

2. Xavier BB, Lammens C, Ruhal R, Kumar-Singh S, Butaye P, Goossens $\mathrm{H}$, et al. Identification of a novel plasmid-mediated colistin-resistance gene, $m c r-2$, in Escherichia coli, Belgium, June 2016. Euro Surveill. 2016;21:30280. http://dx.doi.org/ 10.2807/1560-7917.ES.2016.21.27.30280

3. Poirel L, Jayol A, Nordmann P. Polymyxins: antibacterial activity, susceptibility testing, and resistance mechanisms encoded by plasmids or chromosomes. Clin Microbiol Rev. 2017;30:557-96. http://dx.doi.org/10.1128/CMR.00064-16

4. Liassine N, Assouvie L, Descombes MC, Tendon VD, Kieffer N, Poirel L, et al. Very low prevalence of MCR-1/MCR-2 plasmid-mediated colistin resistance in urinary tract Enterobacteriaceae in Switzerland. Int J Infect Dis. 2016;51:4-5. http://dx.doi.org/10.1016/j.ijid.2016.08.008

5. Irrgang A, Roschanski N, Tenhagen BA, Grobbel M, Skladnikiewicz-Ziemer T, Thomas K, et al. Prevalence of $m c r-1$ in E. coli from livestock and food in Germany, 2010-2015. PLoS One. 2016;11:e0159863. http://dx.doi.org/10.1371/ journal.pone.0159863

6. Guenther S, Falgenhauer L, Semmler T, Imirzalioglu C, Chakraborty T, Roesler U, et al. Environmental emission of multiresistant Escherichia coli carrying the colistin resistance gene $m c r-1$ from German swine farms. J Antimicrob Chemother. 2017;72:1289-92.

7. Huang X, Yu L, Chen X, Zhi C, Yao X, Liu Y, et al. High prevalence of colistin resistance and $m c r-1$ gene in Escherichia coli 
isolated from food animals in China. Front Microbiol. 2017;8:562. http://dx.doi.org/10.3389/fmicb.2017.00562

8. Perrin-Guyomard A, Bruneau M, Houée P, Deleurme K, Legrandois P, Poirier C, et al. Prevalence of $m c r-1$ in commensal Escherichia coli from French livestock, 2007 to 2014. Euro Surveill. 2016;21:30135. http://dx.doi.org/10.2807/1560-7917. ES.2016.21.6.30135

9. Zhang C, Feng Y, Liu F, Jiang H, Qu Z, Lei M, et al. A phage-like IncY plasmid carrying the $m c r-1$ gene in Escherichia coli from a pig farm in China. Antimicrob Agents Chemother. 2017;61: e02035-16. http://dx.doi.org/10.1128/AAC.02035-16

10. Xavier BB, Lammens C, Butaye P, Goossens H, Malhotra-Kumar S. Complete sequence of an IncFII plasmid harbouring the colistin resistance gene $\mathrm{mcr}-1$ isolated from Belgian pig farms. J Antimicrob Chemother. 2016;71:2342-4. http://dx.doi.org/10.1093/jac/dkw191

11. Poirel L, Kieffer N, Brink A, Coetze J, Jayol A, Nordmann P. Genetic features of MCR-1-producing colistin-resistant Escherichia coli isolates in South Africa. Antimicrob Agents Chemother. 2016;60:4394-7. http://dx.doi.org/10.1128/AAC.00444-16

12. Zurfluh K, Kieffer N, Poirel L, Nordmann P, Stephan R. Features of the $m c r-1$ cassette related to colistin resistance. Antimicrob Agents Chemother. 2016;60:6438-9. http://dx.doi.org/10.1128/ AAC.01519-16

13. Poirel L, Kieffer N, Nordmann P. In-vitro study of ISApll-mediated mobilization of the colistin resistance gene $\mathrm{mcr}$ - 1 . Antimicrob Agents Chemother. 2017;61:e00127-17. http://dx.doi.org/10.1128/ AAC.00127-17

14. Zurfluh K, Klumpp J, Nüesch-Inderbinen M, Stephan R. Fulllength nucleotide sequences of $m c r-1$-harboring plasmids isolated from extended-spectrum- $\beta$-lactamase-producing Escherichia coli isolates of different origins. Antimicrob Agents Chemother. 2016;60:5589-91. http://dx.doi.org/10.1128/AAC.00935-16

15. Kieffer N, Nordmann P, Poirel L. Moraxella species as potential sources of MCR-like polymyxin-resistance determinants. Antimicrob Agents Chemother. 2017;61:e00129-17. http://dx.doi.org/10.1128/AAC.00129-17

16. Poirel L, Kieffer N, Fernandez-Garayzabal JF, Vela AI, Larpin Y, Nordmann P. MCR-2-mediated plasmid-borne polymyxin resistance most likely originates from Moraxella pluranimalium. J Antimicrob Chemother. In press; 2017.

17. Vela AI, Sánchez-Porro C, Aragón V, Olvera A, Domínguez L, Ventosa A, et al. Moraxella porci sp. nov., isolated from pigs. Int J Syst Evol Microbiol. 2010;60:2446-50. http://dx.doi.org/ 10.1099/ijs.0.016626-0

18. Rhouma M, Beaudry F, Thériault W, Letellier A. Colistin in pig production: chemistry, mechanism of antibacterial action, microbial resistance emergence, and One Health perspectives. Front Microbiol. 2016;7:1789. http://dx.doi.org/10.3389/ fmicb.2016.01789

19. Katsunuma Y, Hanazumi M, Fujisaki H, Minato H, Hashimoto Y, Yonemochi C. Associations between the use of antimicrobial agents for growth promotion and the occurrence of antimicrobial-resistant Escherichia coli and enterococci in the feces of livestock and livestock farmers in Japan. J Gen Appl Microbiol. 2007;53:273-9. http://dx.doi.org/10.2323/jgam.53.273

20. Quesada A, Ugarte-Ruiz M, Iglesias MR, Porrero MC, Martínez R, Florez-Cuadrado D, et al. Detection of plasmid mediated colistin resistance (MCR-1) in Escherichia coli and Salmonella enterica isolated from poultry and swine in Spain. Res Vet Sci. 2016;105:134-5. http://dx.doi.org/10.1016/ j.rvsc.2016.02.003

21. Falgenhauer L, Waezsada SE, Yao Y, Imirzalioglu C, Käsbohrer A, Roesler U, et al.; RESET Consortium. Colistin resistance gene $m c r-1$ in extended-spectrum $\beta$-lactamase-producing and carbapenemase-producing Gram-negative bacteria in Germany.
Lancet Infect Dis. 2016;16:282-3. http://dx.doi.org/10.1016/ S1473-3099(16)00009-8

22. Catry B, Cavaleri M, Baptiste K, Grave K, Grein K, Holm A, et al. Use of colistin-containing products within the European Union and European Economic Area (EU/EEA): development of resistance in animals and possible impact on human and animal health. Int $\mathrm{J}$ Antimicrob Agents. 2015;46:297-306. http://dx.doi.org/10.1016/ j.ijantimicag.2015.06.005

23. Conceição T, de Lencastre H, Aires-de-Sousa M. Frequent isolation of methicillin resistant Staphylococcus aureus (MRSA) ST398 among healthy pigs in Portugal. PLoS One. 2017;12:e0175340. http://dx.doi.org/10.1371/journal.pone.0175340

24. Nordmann P, Jayol A, Poirel L. A universal culture medium for screening polymyxin-resistant Gram-negative isolates. J Clin Microbiol. 2016;54:1395-9. http://dx.doi.org/10.1128/ JCM.00446-16

25. Clinical and Laboratory Standards Institute. Performance standards for antimicrobial susceptibility testing; 26th informational supplement (M100-S26). Wayne (PA): The Institute; 2016.

26. Lartigue MF, Poirel L, Nordmann P. Diversity of genetic environment of bla $a_{\text {СTX-M }}$ genes. FEMS Microbiol Lett. 2004; 234:201-7. http://dx.doi.org/10.1111/j.1574-6968.2004.tb09534.x

27. Kim J, Lim YM. Prevalence of derepressed $\operatorname{ampC}$ mutants and extended-spectrum $\beta$-lactamase producers among clinical isolates of Citrobacter freundii, Enterobacter spp., and Serratia marcescens in Korea: dissemination of CTX-M-3, TEM-52, and SHV-12. J Clin Microbiol. 2005;43:2452-5. http://dx.doi.org/ 10.1128/JCM.43.5.2452-2455.2005

28. Poirel L, Kieffer N, Liassine N, Thanh D, Nordmann P. Plasmid-mediated carbapenem and colistin resistance in a clinical isolate of Escherichia coli. Lancet Infect Dis. 2016;16:281. http://dx.doi.org/10.1016/S1473-3099(16)00006-2

29. Kieffer N, Nordmann P, Aires-de-Sousa M, Poirel L. High prevalence of carbapenemase-producing Enterobacteriaceae among hospitalized children in Luanda, Angola. Antimicrob Agents Chemother. 2016;60:6189-92. http://dx.doi.org/10.1128/ AAC.01201-16

30. Clermont O, Christenson JK, Denamur E, Gordon DM. The Clermont Escherichia coli phylo-typing method revisited: improvement of specificity and detection of new phylo-groups. Environ Microbiol Rep. 2013;5:58-65. http://dx.doi.org/10.1111/ 1758-2229.12019

31. Carattoli A, Bertini A, Villa L, Falbo V, Hopkins KL, Threlfall EJ. Identification of plasmids by PCR-based replicon typing. J Microbiol Methods. 2005;63:219-28. http://dx.doi.org/10.1016/ j.mimet.2005.03.018

32. Kieser T. Factors affecting the isolation of CCC DNA from Streptomyces lividans and Escherichia coli. Plasmid. 1984;12:1936. http://dx.doi.org/10.1016/0147-619X(84)90063-5

33. Nordmann P, Assouvie L, Prod'Hom G, Poirel L, Greub G. Screening of plasmid-mediated MCR-1 colistin-resistance from bacteremia. Eur J Clin Microbiol Infect Dis. 2016;35:1891-2. http://dx.doi.org/10.1007/s10096-016-2739-0

34. Jiang X, Poirel L, Nordmann P. Lack of polymyxin resistance among carbapenemase-producing Enterobacteriaceae in a university hospital in China. Infect Dis (Lond). 2017;49:556-7. http://dx.doi.org/10.1080/23744235.2017.1292543

35. Buess S, Nüesch-Inderbinen M, Stephan R, Zurfluh K. Assessment of animals as a reservoir for colistin resistance: no MCR-1/MCR-2-producing Enterobacteriaceae detected in Swiss livestock. J Glob Antimicrob Resist. 2017;8:33-4. http://dx.doi.org/ 10.1016/j.jgar.2016.11.001

36. Malhotra-Kumar S, Xavier BB, Das AJ, Lammens C, Butaye P, Goossens H. Colistin resistance gene $m c r-1$ harboured on a multidrug resistant plasmid. Lancet Infect Dis. 2016;16:283-4. http://dx.doi.org/10.1016/S1473-3099(16)00012-8 
37. Falgenhauer L, Waezsada SE, Gwozdzinski K, Ghosh H, Doijad S, Bunk B, et al. Chromosomal locations of $\mathrm{mcr}-1$ and bla $_{\text {СTX-M-15 }}$ in fluoroquinolone-resistant Escherichia coli ST410. Emerg Infect Dis. 2016;22:1689-91. http://dx.doi.org/10.3201/ eid2209.160692

38. Saly M, Jayol A, Poirel L, Mégraud F, Nordmann P, Dubois V. Prevalence of faecal carriage of colistin-resistant Gram-negative rods in a university hospital in western France, 2016. J Med Microbiol. 2017;66:842-3. http://dx.doi.org/10.1099/jmm.0.000497

39. Campos J, Cristino L, Peixe L, Antunes P. MCR-1 in multidrugresistant and copper-tolerant clinically relevant Salmonella 1,4,[5],12:i:- and $S$. Rissen clones in Portugal, 2011 to 2015. Euro Surveill. 2016;21:30270. http://dx.doi.org/10.2807/ 1560-7917.ES.2016.21.26.30270

40. Bernasconi OJ, Kuenzli E, Pires J, Tinguely R, Carattoli A, Hatz C, et al. Travelers can import colistin-resistant Enterobacteriaceae, including those possessing the plasmidmediated $m c r-1$ gene. Antimicrob Agents Chemother. 2016;60:5080-4. http://dx.doi.org/10.1128/AAC.00731-16

41. Yang RS, Feng Y, Lv XY, Duan JH, Chen J, Fang LX, et al. Emergence of NDM-5- and MCR-1-producing Escherichia coli clones ST648 and ST156 from a single muscovy duck (Cairina moschata). Antimicrob Agents Chemother. 2016;60:6899-902. http://dx.doi.org/10.1128/AAC.01365-16

42. He QW, Xu XH, Lan FJ, Zhao ZC, Wu ZY, Cao YP, et al. Molecular characteristic of $m c r-1$ producing Escherichia coli in a Chinese university hospital. Ann Clin Microbiol Antimicrob. 2017;16:32. http://dx.doi.org/10.1186/s12941-017-0207-z

43. Sun J, Fang LX, Wu Z, Deng H, Yang RS, Li XP, et al. Genetic analysis of the IncX4 plasmids: implications for a unique pattern in the $m c r-1$ acquisition. Sci Rep. 2017;7:424. http://dx.doi.org/10.1038/s41598-017-00095-x

44. Snesrud E, He S, Chandler M, Dekker JP, Hickman AB, McGann P, et al. A model for transposition of the colistin resistance gene $m c r-1$ by ISApl1. Antimicrob Agents Chemother. 2016;60:6973-6. http://dx.doi.org/10.1128/AAC.01457-16

Address for correspondence: Laurent Poirel, Medical and Molecular Microbiology Unit, Department of Medicine, Faculty of Science, University of Fribourg, rue Albert Gockel 3, CH-1700 Fribourg, Switzerland; email: laurent.poirel@unifr.ch

\section{etymologia}

\section{Taenia saginata [te'ne-ə saj"e-na'ta]}

\section{Ronnie Henry}

$\mathbf{J}^{\mathrm{oin}}$ ohann Goeze is credited with the first correct description of Taenia [Latin, "flat band" or "ribbon"] saginata [Latin, "fed"], commonly known as the beef tapeworm, in 1782. Historically, Taenia tapeworms were believed to have infected humans no more than 10,000 years ago, around the time of domestication of cows and pigs.

However, more recent phylogenetic evidence suggests that ancestors of modern humans, living on the savannahs of Africa and preying on antelope and other bovids, became colonized with Taenia $>3$ million years ago. Parasite definitive hosts switched from large carnivores (probably hyenas) to hominids through their common prey, and this process triggered the evolution of human-infecting species of Taenia. Humans later spread these parasites to domestic animals.

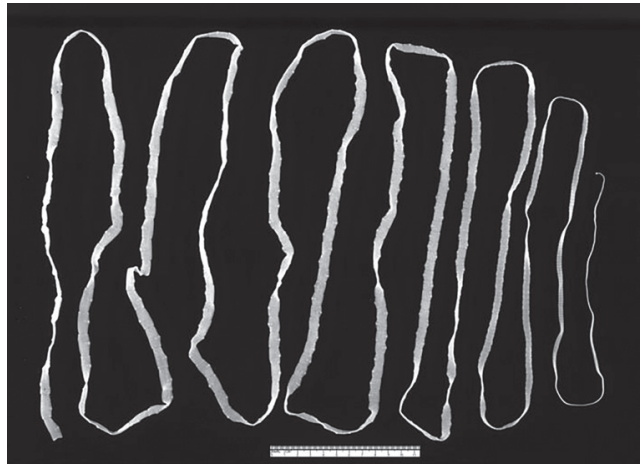

Adult Taenia saginata tapeworm. Photo CDC/1986.

\section{Sources}

1. Despommier DD, Gwadz RW, Hotez PJ. Taenia saginata (Goeze 1782). In: Parasitic Diseases. 3rd ed. New York: Springer; 1995. p.76-80.

2. Hoberg EP, Alkire NL, de Queiroz A, Jones A. Out of Africa: origins of the Taenia tapeworms in humans. Proc Biol Sci. 2001;268:781-7. http://dx.doi.org/10.1098/rspb.2000.1579

3. Terefe Y, Hailemariam Z, Menkir S, Nakao M, Lavikainen A, Haukisalmi V, et al. Phylogenetic characterisation of

Taenia tapeworms in spotted hyenas and reconsideration of the "Out of Africa" hypothesis of Taenia in humans. Int J Parasitol. 2014;44:533-41. http://dx.doi.org/10.1016/ j.ijpara.2014.03.013

4. Zarlenga DS, Hoberg E, Rosenthal B, Mattiucci S, Nascetti G. Anthropogenics: human influence on global and genetic homogenization of parasite populations. J Parasitol. 2014;100:756-72. http://dx.doi.org/10.1645/14-622.1

Address for correspondence: Ronnie Henry, Centers for Disease Control and Prevention, 1600 Clifton Rd NE, Mailstop E28, Atlanta, GA 30329-4027, USA; email: boq3@cdc.gov

DOI: https://doi.org/10.3201/eid2312.ET2312 